\title{
REPORT ON LEPROSY IN ANTIGUA
}

\section{E. MUIR}

On behalf of the British Empire I eprosy Relief Association, I paid a visit to Antigua to study leprosy in the island and advise as to measures for its control. I arrived on the 28 th of January and left on the 3 rd of February, 1942. 
According to a programme drawn up by Dr. John Wright, the Senior Merlical Officer, I visited the I-eper Home in company with Dr. Stevens, the visiting physician of the Home, gave a couple of talks and demonstrations of leprosy to the doctors, exanined a number of leprosy patients who are not interned in the I-eper Home and their contacts, and addressed a public meeting.

\section{I.EPER HOME.}

This institution, which was formerly on Rat Island in St. John's Harbour, is now at Pearns, on the west coast, to the S.W. of St. John's, from which it is about six miles distant hy road.

\section{ACCOMMODATION.}

This consists of a number of two-roomed buildings each with a gallery. Each patient has a separate room. The walls and roofs are built of asbestos sheeting, the latter being lined with wood. The patients complain that they are too cold in cold weather and too hot in hot weather. Two new buildings have been added recently, each consisting of six rooms, of which the three in front back on the three behind. This seems to be a bad arrangement, as the middle room on each side has no through ventilation.

There is a kitchen, where the food is prepared by two female cooks and a kitchen maid. Meals are served either in the dinino shed or in the patients' own rooms. The diet seems to he fairly good, especially as fresh vegetables are obtained from the patients' gardens and as fresh fish is frequently given.

\section{Patients.}

I examined the 2 I male and 17 female patients and classified them roughly as follows:

\begin{tabular}{|c|c|c|c|c|c|c|c|}
\hline $\begin{array}{l}\text { Type. } \\
\mathrm{N}_{-1} \text { with minor }\end{array}$ & tuberculc & & esions & $\ldots$ & $\underset{\mathbf{I}}{\text { Male. }}$ & $\underset{\mathbf{o}}{\text { Female. }}$ & $\underset{\mathbf{I}}{\text { Total. }}$ \\
\hline $\mathrm{N}-2$ & do. & & & $\ldots$ & 3 & 1 & 4 \\
\hline $\mathrm{N}-3$ & do. & & & $\ldots$ & 3 & 2 & 5 \\
\hline $\mathrm{N}_{-3}^{-3}$ with simple & lesions & $\cdots$ & $\cdots$ & $\ldots$ & I & o & I \\
\hline$\ldots$ & $\ldots$ & $\ldots$ & $\cdots$ & $\ldots$ & o & $\mathbf{I}$ & I \\
\hline $\mathrm{L}-3$ & $\ldots$ & $\ldots$ & $\cdots$ & $\cdots$ & 9 & 7 & 16 \\
\hline $\mathrm{L}-\mathrm{I}, \quad \mathrm{N}-3$ & $\ldots$ & $\ldots$ & $\ldots$ & $\cdots$ & o & I & 1 \\
\hline Disease arrested & $\ldots$ & $\cdots$ & $\cdots$ & $\cdots$ & 3 & 5 & 8 \\
\hline Not leprosy & $\cdots$ & $\cdots$ & $\cdots$ & $\cdots$ & o & $\mathrm{I}$ & $\mathbf{x}$ \\
\hline & & & Total & $\ldots$ & 20 & $\overline{18}$ & 38 \\
\hline
\end{tabular}

$[" \mathrm{~N}$ " represents neural and " $\mathrm{L}$ " represents lepromatous. The figures indicate the degree of the disease.7

The majority, 20 of the whole, are non-infectious cases, but a number of these are hopelessly crippled, some of them being permanently confined to their rooms. 


\section{OCCUPATION}

One of the most important parts of the treatment of leprosy is exercise and mental and physical activity. Some 25 of the patients cultivate their own gardens and sell the produce to the Home. In this way they each earn an average of about 2. cents a day. Also, Io men and 8 women are able to earn about $\$ 1.25$ a month on an average by sweeping, scavenging, washing and mending clothes, etc. But these activities are. small compared with the capacity of the patients for work.

Many of the buildings, roads, drains and other structures in and around the Home are in need of repair, reconstruction or extension, and I understand that these works have often been held up for want of labour.

On enquiry I found that there are among the patients a builder and two carpentcrs, and that they would be glad to undertake such work; also six to ten other able-hodied patients would be willing to assist. Such an arrangement would allow for improvement of the institution at a much cheaper rate than could be done by outside labour, and, still more important, it would be very heneficial to the patients by removing the mental and physical stagnation in which they spend much of their time.

In the leprosaria in Trinidad, British Guiana and most of the larger leprosy institutions such work is done by the patients with great benefit. At the same time it would be well if a social worker of the right type could he appointed, part of whose duties would he to organise the work and social life of the patients. I refer again to this later.

The Medical Side.

At present this is attended to by a physician who visits once a week. Dressings and general care of the patients are looked after by three untrained women who act as nurses. The Superintendent formerly belonged to the Government Printing Department, but has, I understand, no training in tending the sick.

The visits of the physician are hampered by the bad condition of the branch road joining up the main road with the Home. This might be remedied at small cost by employing patient labour in repairs. Unlike the custom in the other Government I eper Homes I have visited, the physician receives no extra remuneration for his services.

I think it important that the physician in charge should have an opportunity of studying leprosy for two months in a suitable centre such as that in Trinidad. 
In place of one of the female nurses a hetter educated and trained male nurse might he appointed, who would also organise social and other activities of the patients. Such a man would necessarily he carefully selected, an important qualification being that he was interested in the patients and their welfare. He might he given special training in dispensing, dressing, etc., at the hospital, and might with advantage he sent for a period of training to one of the larger leprosaria.

It is important that all patients should he examined and treated for complicating diseases, the presence of which often prevents improvement under special anti-leprosy treatment.

If these improvements and those mentioned under "Occupation" were carried out, the I eper Home would hecome a much more attractive place, and patients would be more likely to seek voluntary admission.

\section{T.EPROSY CONTROL.}

\section{Segreation and Domiciliary Isolation.}

Under the I.eper Act, as amended in 1937, provision is mate for compulsory segregation in the I.eper Home of those dully certified as suffering from leprosy. An exception, however, may he made "if the person suffering from leprosy is in the opinion of the Governor, able to provide for himself outside a I.eper Home, effective isolation in accordance with rules made under the Act and subject to security heing given by bond" in a sum of $£ 50$.

In Antigua apparently oreat use has been made of this nrovision, and I am informed that a large number of lepers have heen allowed to remain at their own residences.

There are two ohiects for which a leper is sent to a I.eper Home: the public object of preventing him from spreading infection, and the personal one of securing for him proper treat. ment. care and nourishment.

In the I-eper Act there is no recognition of the important difference between "open" or infectious cases, and "closed" or non-infectious cases. As the latter do not spread infection, thev are sent to the I.eper Home. for their personal care alone. It is noted above that 20 out of the 38 cases at present in the Home come under this category. Of these, the patients able to provide for their own care and treatment at home might safelv be discharged.

The provision which allows for domiciliary isolation of cases at their own homes, whether they are "open" or not, requires verv careful consideration and revision. A distinction should be made hetween the two categories. 
The "closed" cases (that is to say, those giving negative findings on repeated exammations by the routme methods of skin and nasal mucous membrane) will not spread infection, and need not be compulsorlly segregated. 'T hey should, however, be kept under suitable inspection in case they should become infectious in future.

"Upen" cases, however, are in a very different position. The Leper Act of this Colony is based upon that of British liuiana, where there is a whole-time leprosy expert who is not only the Niedical Supermtendent of the Leper Home, but has lor many years been in touch with all the cases under treatment outside. Moreover, in the British Luiana leprosy institution special provision is made for suitably housing better-class patients who are also attracted by the experience of others over many years that hope of recovery is much greater inside than outside the institution.

Unfortunately this cannot be said of Antigua, chiefly on account of the fact that the Leper Home is too small to allow for the provision of a whole-time physician. The visiting physician has innumerable other duties, so that he can rarely visit more than once a weck, nor has he had time or opportunity to acquire the experience necessary in treating so difficult a disease as leprosy.

A suggestion has been made that hopeful cases should be sent for treatment to one of the larger leprosaria; the difficul. ties in the way of this are: arrangements for transport, amending of laws preventing immigration of lepers, the hardship of distant separation from relatives.

\section{Recommendations.}

I recommend that:

(1) All cases be divided into "open" and "closed" categories;

(2) Only those "closed" cases to be sent to the Leper Home who are unable or unwilling to make suitable arrangements at home.

The patient remaining at home should either be visited once a week by a medical officer appointed by the Senior Medical Officer or attend weekly at a place appointed by the Senior Medical Officer. He should remain under inspection and treatment as long as signs of active disease persist. Thereafter he should be inspected at least once in three months for a period of three years. 
(3) The "open" case should be sent to the Leper Home unless he remain under the following rules:

(a) I urnish security as under the present Act;

(b) Be visited for inspection and treatment at his home once a week by a medical officer appointed by the Senior Medical Ufficer;

(c) Live in a house easily accessible to the visiting medical officer, but at an approved distance lrom the nearest other dwelling. The medical officer will be satisficd that the house is kept clean and hygienic inside and in its surroundings. There will be separate sanitary and bathing arrangements for the patient not used by his attendants or others. The patient's room, furniture, linen, eating and drinking utensils will $r_{1}$ ot be used by others. There will be at least one aciult attendant of over 30 years of age, who has been approved by the visiting medical officer as suitable. Adults will be allowed to visit the patient, but no children under 15 years of age. The attendants and visitors will be warned by the medical officer of the danger of close contact or of using furmiture, utensils, etc., used by the patient.

(4) The "open" patient will not enter any shop or building except his own home. He may take exercise in the open country as approved by the medical officer.

(5) If the medical officer finds that the patient is not co-operating and taking the precautions prescribed, he will report to the Senior Medical Officer.

(6) Previous contacts of the patient, especially children will be put on a list for periodic inspection for leprosy.

\section{LEPROSY SURVEY.}

Before this can be satisfactorily undertaken two things seem necessary:

(a) That at least one medical officer should spend about one or more months in Trinidad or British Guiana studying leprosy and the methods of its control;

(b) The setting up of the Heaith Unit System as proposed by the Medical Adviser to the Comptroller of the West Indies Welfare Fund.

It would then be possible gradually to carry out a leprosy 
survey, by placing coritacts of lepers, especially children, on a list for periodic examinations, by including the detection of leprosy in examination of schoolchildren.

\section{CONCLUSION.}

Leprosy is not one of the most serious problems in the Presidency. There are, however, two reasons why it should receive precedence in an attempt to eradicate it:

(1) The horror and mental suffering which it produces;

(2) The fact that by taking energetic measures along the right lines it could be eradicated in a comparatively short time.

\section{ACKNOWLEDGMENTS.}

1 wish to thank His Excellency the Governor for the interest and help he has given, the Senior Medical Officer and nis staff and others for assistance $\mathrm{nl}$ planning my visit to Antigua and carrying out its objects. 